\title{
Food wastage management at the South African Military Academy officers' mess
}

\author{
Nomboniso Moss, Ivan Henrico and Hennie Smit ${ }^{374}$ \\ Stellenbosch University
}

\begin{abstract}
Globally, an estimated one-third of the total of food produced for human consumption is never consumed. This affects food security. South Africa has obligations to meet international commitments to reduce food wastage. The United Nations Sustainable Development Goal (SDG) 12.3 aims to reduce food loss through wastage by 30 per cent by 2030. To contribute to the achievement of this goal, South Africa has to formulate policies to reduce food loss to achieve national food security. The South African National Defence Force (SANDF), as an organ of the state, should align with national policies aimed at reducing food loss and waste. The current study was conducted at the South African Military Academy (SAMA), an institution of higher learning for SANDF members. The institution has a catering facility that serves approximately 350 resident students and other living-in members ${ }^{375}$ daily. To date, no research has been done on food wastage management either in the broader SANDF or at this institution. This lack of information and analysis on food wastage management in the military in South Africa prompted the current research. The study analysed food wastage management at the SAMA mess to identify the level of knowledge and skills of SAMA officers' mess personnel regarding the status of food wastage and best management practices. Through this qualitative study, online semi-structured interviews, using Microsoft Teams, were utilised to collect data from SAMA mess personnel. The findings revealed that there are set measures in place at the SAMA mess for managing food wastage, such as booking meals in advance and being able to repurpose food. The participants also indicated that most SAMA chefs are trained in food wastage management and possess the necessary skills to reduce food wastage in the mess; yet, not optimally so. Recommendations from this research are that more and improved training of personnel, as well as awareness programmes among mess staff and SAMA students would further reduce food wastage. Implementing such food wastage management measures would benefit the SAMA and the SANDF, and would contribute to national food wastage management and the realisation of the United Nations SDG 12.3.
\end{abstract}

Keywords: Food security, food wastage, food wastage management, South African Military Academy, semi-structured interviews

\section{Introduction}

According to the Food and Agricultural Organization (FAO) of the United Nations, ${ }^{376}$ statistics on food loss and food wastage calculated from the post-harvest stage indicates that about 14 per cent of food produced never reaches retail shelves or the consumer. Historically, food supply for human consumption depends on three systems, namely 
croplands, which mostly produce grains; rangelands that produce meat from grazing livestock; and ocean fisheries which generate the world's fish. ${ }^{377}$ Society nurtures the natural resources produced, and shapes the products that we consume. ${ }^{378}$ Rapid urbanisation and population growth have contributed to increased global food production in urban areas due to considerable changes in people's dietary plans and the related increased demand for food. ${ }^{379}$ Within this production, food loss and food wastage start with agricultural production and continues right through to human consumption. ${ }^{380}$ Most of the food wasted during the consumption stage takes place in high-income countries, and the amount and type of consumption are directly proportionate to household wealth. $^{381}$

A significant amount of food wastage during human consumption is produced by the hospitality sector. ${ }^{382}$ This sector comprises restaurants, pubs, educational facilities with a residential component, hotels, healthcare and nourishment facilities, catering, and military training, operational and housing services. ${ }^{383}$

The Department of Defence secures catering services for the SANDF, both at static bases and at temporary bases during special operations. In the SANDF, food waste is disposed of through a waste disposer attached to the kitchen drain, which collects food waste as pigswill. ${ }^{384}$ Standard procedures for the disposal of food are required to ensure that the hygiene, health and safety of mess staff and living-in members are not compromised.

The SAMA is an institute of higher learning, mandated by the SANDF to develop and educate young officers. ${ }^{385}$ It has a hospitality section (mess facility) that caters for three meals per day for the approximately 350 members (students and staff) residing in military accommodation inside the unit. Food wastage in the hospitality sector occurs in any one area or in a combination of three streams: during the preparation of food, during food consumption, and during discarding leftover food. Whenever food ends up as waste, it means that not just the food product, but the water, energy and resources that had been used to produce such food have been wasted as well. ${ }^{386}$

Ideally, food wastage management (FWM) should prevent waste generation in the first place. ${ }^{387}$ From a geographical perspective, FWM consists of managing the environment, specifically relating to the landfill disposal of food. SAMA is located in a conservation area with vulnerable and endangered species, such as the black harrier. ${ }^{388}$

Bearing in mind environmental concerns, the area where food disposal occurs needs to be kept free from pollution by any kind of waste to ensure the conservation of biodiversity. Suboptimal or ineffective FWM could lead to financial losses, environmental degradation, unpleasant smells and diseases, and the food waste site itself might become a breeding ground for insects, and attracting stray animals, such as dogs and cats. It is therefore important to ensure the correct management of food wastage through all phases of handling of food at the SAMA mess.

Globally, food loss and wastage have been a growing topic of discussion on different platforms due to its environmental, economic and social implications. ${ }^{389}$ Annually, South Africa generates about nine million tonnes of food wastage, which amounts to 29 per 
cent of the local agricultural production. ${ }^{390}$ Oelofse and Nahman found that the bulk of this wasted food (8.67 million tonnes per annum or 95.9 per cent) is generated during the pre-customer phase. ${ }^{391}$

Additionally, an estimated 1 billion South African rand (ZAR) worth of energy is wasted during the production of food that will eventually be wasted. This figure includes fuel and electricity costs used for producing and preparing the food. ${ }^{392}$ Nahman and De Lange conducted research on the cost of household food wastage in South Africa and found that roughly 21.7 billion South African rand (ZAR) or 0.8 per cent of the gross domestic product (GDP) is wasted by South African households in the form of food every year. ${ }^{393}$

Most previous research on food wastage focused on institutions of learning and higher learning (universities and other), hotels, restaurants and hospitals. ${ }^{394}$ A study by Marais et al. (2017) investigated the extent of food wastage by Stellenbosch University students in their respective residences. The study also researched attitudes and practises of food service managers, catering personnel and students, which affected food wastage. The findings indicated that high food wastage was influenced substantially by the meal booking system, related menu planning, and the meal serving format and style. ${ }^{395} \mathrm{~A}$ similar study was conducted by Mabaso and Hewson (2018) on employees' perceptions of FWM in hotel kitchens, focusing on a hotel group in Gauteng, South Africa. The findings revealed that the employees understood the implications of food wastage and that they contributed positively towards addressing issues relating to food wastage. ${ }^{396}$

To date, no research has been conducted on the wastage of food and FWM at the SAMA. There are also no known studies related to this issue in the SANDF, the mother organisation of this institution. This lack of an empirical study regarding FWM in the SANDF in general, and at the SAMA in particular, presented a research gap worth investigating, since South Africa is part of Target 12.3 of the United Nations SDGs (UNSDG), which is committed to reducing food wastage by 30 per cent by $2030 .{ }^{397}$ The results of research on food wastage at the SAMA will contribute to improved FWM at the SAMA, as well as in the broader SANDF.

In this article, the literature applicable to FWM in general, and to FWM in a military context specifically, will be introduced. The methods used to gather information on FWM at the SAMA mess are explained thereafter, and the recorded views of participants regarding FWM are reported. The article is concluded by revisiting the results of the study and discussing the implications of the results, drawing conclusions from the data collected, highlighting limitations, and recommending measures to enhance FWM at the SAMA mess.

\section{Food wastage in a military context}

In the following subsections, the concept of food wastage is illuminated, the types of food wastage identified, and the causes of food wastage explained. This is followed by a discussion of the consequences associated with food wastage, and effective and/or noneffective FWM in the South African National Defence Force (SANDF). 
Defining food wastage

The Global Food Waste Management Report defines food as -

[A]ny substance processed, semi-processed or raw that is needed for human consumption as well as edible parts associated with food that is not intended to be consumed by humans. ${ }^{398}$

Waste is defined as -

[A]ny substance, material or object, that is unwanted, rejected, abandoned, discarded or disposed of, or that is intended or required to be discarded or disposed of, by the holder of that substance, material or object, whether or not such substance, material or object can be reused, recycled or recovered. ${ }^{399}$

According to Priestley (2016), there is no legal or universal definition of food wastage. She states that food wastage studies normally include varied methodologies, reporting and discussion that cannot be compared directly. ${ }^{400}$ The FAO, however, describes food wastage as "food appropriate for human consumption being discarded, whether or not after it is kept beyond its expiry date or left to spoil". Riley defines food wastage as "raw or cooked food materials and includes food loss, before, during or after meal preparation in the household, as well as food discarded in the process of manufacturing, distribution, retail, and food service activities". ${ }^{401}$ These definitions are similar, and address discarded food at customer level. A more recent definition of food wastage was created by the FAO after consulting experts to synchronise definitions of food wastage. The FAO differentiates between food loss and food wastage. Food loss is defined as "the decrease in the quantity or quality of food resulting from decisions and actions by food suppliers in the chain, excluding retailers, food service providers and consumers" and food wastage is defined as "the decrease in the quantity or quality of food resulting from decisions and actions by retailers, food service and consumers". ${ }^{402}$

From the above definitions, one can deduce that food wastage is any consumable material meant for humans that ends up being discarded for any reason. The operational definition of food wastage adapted for this study is ' $[\mathrm{w}]$ asted food is any unwanted or discarded food at the SA Military Academy mess that was meant for human consumption and is now at the point of being disposed of.'

\section{Types of food wastage}

Food disposed of as waste can be divided into avoidable and unavoidable waste. Avoidable food wastage is food and drink that were discarded because of inefficient or ineffective food management, which at the point of disposal was still fit for human consumption. ${ }^{403}$ This includes food damaged during food preparation, such as burnt food or food which expired before consumption. This type of wastage can be prevented through better planning and an effective estimation of food prepared per meal, per day in the kitchen. ${ }^{404}$ According to Enos (2019), fresh fruit and vegetables are among the most wasted items in the world because of their relatively short shelf life. ${ }^{405}$ 
Unavoidable food wastage refers to food, which is non-edible at the time of disposal. ${ }^{406}$ This includes peels, leftover food, rotten food, food that goes bad before its anticipated expiry date, and raw meat bones. This food can be managed by converting it into animal feed and through resource recovery. ${ }^{407}$

Being able to identify the difference between avoidable and unavoidable food wastage, will assist relevant food managers in monitoring and controlling food wastage, and will contribute to finding alternative ways of curtailing food wastage. The current study mainly focused on avoidable food wastage.

\section{Causes of food wastage}

Globally, food loss and food wastage occur during agricultural production, post-harvest handling and storage, and during consumption (see Figure 1). The first level at which food loss and wastage occurs is the agricultural production level. Here, food loss and food wastage are influenced by ineffective soil preparation, unsuitable harvest timing, adverse weather conditions, compromised seed quality, and pest infections. ${ }^{408}$ Food loss and food wastage also occur during mass production and mass distribution of food. A lack of transportation and storage infrastructure from the place of production to the place of consumption, also contributes to food loss and wasting of food. ${ }^{409}$

At wholesale and retail level, food wastage is caused by the difficulty in forecasting demand, overstocking, staff behaviour towards food and food wasting, and the inappropriate ordering of food. ${ }^{410}$ In highly developed countries, food loss also occurs due to consumable food not meeting retailers' quality standards. In such countries, retailers sell only perfectly produced perishable food and discard substandard food. Retailers focus on the affordability status of food; i.e. food that can be easily replaced, easily disposed of or waste consumable food. ${ }^{411}$ In developing countries, such as subSaharan countries, food loss occurs mainly not at the consumer level, but due to a lack of storage space, inadequate packaging, and unfit storage conditions (e.g. poor temperature control). Globally, fruit and vegetables contribute 15 per cent to food loss and wastage, while in sub-Saharan Africa, this is estimated at 35 per cent - mainly due to the lack of suitable storage. ${ }^{412}$

At consumption level, food wastage is higher in developed countries than in developing countries. This is caused by those who can afford engaging in impulse spending, practising poor storage, and preparing more food than is required. ${ }^{413}$ Food wastage also occurs because food is not consumed before the expiry date. This might be due to oversight or not correctly differentiating between 'best before' and 'consume by' dates of food. Other causes of food wastage include stockpiling, breakages, not preserving food once opened, and package failure. Furthermore, poor cooking skills, serving excessive portions of food, and over-ordering takeaways ultimately lead to waste. ${ }^{414}$ Generally, people are not aware of the amount of food they regularly waste. ${ }^{415}$

In the hospitality sector, a larger amount of food wastage is produced in the kitchen than other types of solid waste. This is caused by poor planning in food acquisition, overcooking, food left on plates, and not allowing customers to take food home, 
especially in buffet eateries, which involves cooking large amounts of an equally large variety of food without certainty of patron numbers or their consuming capacity. ${ }^{416}$ This uncertainty creates increased pressure on natural resources, hinders the cost-effective use of food, and necessitates the disposal of huge amounts of food as waste. ${ }^{417}$

\section{The consequences associated with food wastage}

Food loss and food wastage affect the physical quantity and economic value of available food. According to the FAO's Food Loss Index (FLI) and in terms of economic value, the latest estimation (Food and Agriculture Organization of the United Nation (FAO), 2019) shows that approximately 14 per cent of food produced globally is lost after harvesting (not including the retail level). According to the FAO (2019), at 21 per cent, Central and Southern Asia are the largest contributors to food wastage in the world in terms of economic value. Globally, the second-largest contributors to food (continentwise) are North America and Europe with 16 per cent in economic value lost, which accounts to 12 per cent loss in calories, globally. In sub-Saharan Africa, the economic value (FLI) of food loss is 14 per cent, and the loss of nutritional value (measured in calories) is 17 per cent. ${ }^{418}$

A survey conducted by the FAO in 2016 across the commodity groups and value chain, measured the economic waste from post-harvest to distribution. This study found that the major contribution to food wastage comprised highly perishable commodities, namely roots, tubers, and oil-bearing crops at 26 per cent, followed by fruit and vegetables at 22 per cent. Meat and animal products accounted for 12 per cent and cereal and pulses (beans, peas and lentils), 8 per cent of food wastage. ${ }^{419}$ From the abovementioned reasons for food wastage and the descriptions of food wastage, it is evident that food wastage is not an issue that can be viewed in isolation, but should be addressed holistically. It affects the environment, the economy, and society at large. ${ }^{420}$

It is worth mentioning that in 2012, an estimated amount of 88 million tonnes of food wastage was generated in Europe, estimated at a loss in monetary terms of approximately 143 billion euros (approximately ZAR 2.9 trillion). Of the 88 million tonnes of food wastage, 19 per cent occurred at the food processing level and 53 per cent at the household level. ${ }^{421}$ The United States of America is also one of the major contributors to food wastage. In 2010, an estimated 31 per cent of the 430 billion pounds (= approximately 195 billion $\mathrm{kg}$ ) (worth approximately ZAR 10 trillion) of food generated in the United States for humans was wasted, never even available for consumption. ${ }^{422}$

Food wastage is a global concern because of the impact it has on the environment and on natural resources. ${ }^{423}$ Around the world, soil is eroded due to deforestation when forests are converted into crop-yielding farmland instead of it being used as natural grazing land for animals. ${ }^{424}$ Another concern is the release of greenhouse gas emissions caused by the decomposition of discarded food, which relates to ineffectively managed landfills. ${ }^{425}$ However, not only does food wastage contaminate soil, waterways and groundwater via runoffs when dumped in landfills, it also contributes significantly to water wastage during food production. Water is the source of life and essential to sustain plants towards 
harvest time and to sustain livestock, but is also used during the production of food. Kibria (2017) states that 1500 litres of water are required to produce one kilogramme of rice, 500 litres are required to produce one kilogramme of potatoes, 1000 litres for one litre of milk and astonishingly, 16000 litres of water are used to produce one hamburger. Kibria (2017) furthermore states, "conservative estimates of water loss caused by discarded food indicate that about half of the water withdrawn for irrigation is lost" ${ }^{426} \mathrm{It}$ is evident from the above-mentioned descriptions that food wastage not only affects the environment and natural resources, but also has considerable financial implications for which society and future generations have to pay.

In economic terms, food wastage contributes to increased food prices and consequently reduces the number of people who can afford to eat healthy food. ${ }^{427}$ In the case of the hospitality sector, food wastage results in a loss of costs to procure and process the food and adds to business expenses of requiring additional labour to dispose of the food. ${ }^{428}$ Food wastage affects all stages in the food supply chain, from the production of raw materials through to consumption. These impacts are generally difficult to notice, but through research and awareness campaigns about food wastage, societies may be alerted to this very important aspect of human security. The economic value of the food wasted along the food supply chain can never be recovered, which affects both low-income and high-income countries at different stages of the food supply chain. The ultimate outcome of ineffectively managed food wastage is food insecurity for present and future generations. Food insecurity does not necessarily mean the total loss of food, but refers to the imbalance and separation that exists in the availability and access to food on a global scale between rich and poor societies and developed and developing countries. ${ }^{429}$

Food wastage is also shaped by population growth, a shift in dietary preferences, social upbringing, cultural background, and attitudes of people towards wastage. ${ }^{430}$ In addition to losses during the food production stages, food wastage affects the development and prospects of society, such as to build houses or generate recreational areas. Although reducing food wastage may not directly assist in solving food insecurity in developing countries, it does reduce the pressure on limited land, water and biodiversity resources. ${ }^{431}$ The lack of knowledge and awareness of food wastage and ways of reducing this waste leads societies to dispose of food wastage in large quantities continually, oblivious to the consequences on their long-term security, especially when preservation is not a social norm. Evidentially, there is a difference between the consumption of food for luxury versus necessity. Some social and cultural demands entail being served buffet meals, cooking different types of cuisine and being spoilt for choice, while others are compelled to eat what is at their disposal. Some cultures dispose of certain edible, even muchpreferred food types because it is either considered not palatable or it is not condoned in a prescriptive culture. Other people do not believe in eating leftover food; whatever was not consumed, is discarded after each meal.

The consequences associated with food wastage in the hospitality sector, including at military institutions, is well documented in literature ${ }^{432}$ However, no research exists for food wastage and FWM in the SANDF. The next section highlights this matter. 
According to Chapter 4, section 16(1) of the National Environmental Management: Waste Act 59 of 2008, it is the responsibility of the holder of waste to ensure that the minimising measures, such as prevention, reduction, re-use, recycling and landfills are followed in an environmentally sound manner according to the waste management hierarchy by placing the waste with the least negative impact on top of the structure. ${ }^{433}$ The FAO identified a strategy toolkit from most to least environmentally friendly level, which is aimed at reducing the food wastage footprint. ${ }^{434}$ At the time of writing, no such strategy existed within the SANDF.

In some militaries, such as the United States (US) Army, the installation of a food waste tracking system in military kitchens monitor all wastage that takes place. They use technologies that guide the reduction of wastage in the mess, and promote environmental protection. The United States Army is currently using the LeanPath system that can reduce the food loss per person in the mess. LeanPath is a system that concentrates on the avoidance of wastage by utilising a smart meter that examines and classifies the last discarding of food wastage. The LeanPath system considers the weight of disposed food and then records and categorises the food wasted. The data captured by the LeanPath system is transmitted to a client-specific website that can be analysed by the client to ascertain which type of food is wasted most. This information can then be used to determine the food types that consumers prefer. ${ }^{435}$ This is a contribution towards the Net Zero goals for the US Army. They also have Net Zero Water and Net Zero Energy goals, which focus on the reduction of wastage of water and energy. ${ }^{436}$ As explained earlier, reduction in food wastage through effective, fit-for-purpose management contributes to a reduction in both water and energy wastage.

In the SANDF, three types of catering models, namely the conventional model, the commercialised model, and outsourcing, were recommended by the Defence Command Council and have been approved by National Treasury to be implemented in the SANDF. ${ }^{437}$

The conventional model is a static 'cook and serve' type of catering system. ${ }^{438}$ The procurement of food items of the highest quality is centralised in the storage depot of the unit. The unit receives food rations through the nearest depot based on the culinary requirements of the unit. ${ }^{439}$ The state uses contractors in the procurement of food for the military, and the relevant military mess then communicates their food requirements to the contractors. Rations are distributed from a central depot. ${ }^{440}$ The advantage in this process is that there is no need for each unit to procure its own food. The disadvantages are that the state procures food at a relatively high price because it is on contract, and at times, contractors do not deliver food on time, which might affect wastage.

The commercialised model consists of a process to procure rations independently using non-public funds (NPF). The NPF creates a ration account that reflects the funds received from the Department of Defence ration budget and spends towards rations. This process assists in the procurement of food according to the requirements of the unit. It reduces 
the procurement of unnecessary food or stockpiling of food in the mess. ${ }^{441}$ A move towards commercialisation will require the state to move funds to the operational funds of a specific unit for procuring rations. ${ }^{442}$ The benefits of this model are that there is no intermediary in the procurement of rations, ration funds will be managed by the relevant unit, and unit commanders may purchase the rations according to their requirements. This will, therefore, assist the state in a more cost-effective procurement process, and the unit will be minimising the food wastage footprint through sound management of its food requirements.

Outsourcing involves the contracting of specific activities, which could have been provided in-house, to an outside individual or organisation. ${ }^{443}$ This means that a private company will provide the goods and services. This is done when there is a skills gap, a lack of manpower, or when it is more expensive to render food services internal than externally. Outsourcing aims to reduce and control the cost operating measure. ${ }^{444}$

All these models provide a nutritional meal using the ration scale to cater for military personnel according to their physical and professional environmental conditions. The ration scale specifies and quantifies all food items required to plan a menu. ${ }^{445}$ It is essential that the food ordered be of the highest quality, and that the person placing the order be fully informed of the consumer needs. The stock levels of food must be monitored constantly by the ration clerk to avoid buying the same items more than once and to prevent wasteful expenditure for the military. Seasonal food should be favoured, as buying food in season reduces cost. There must be enough storage space for storing and preserving ordered items to reduce possible wastage. The space should be kept neat and hygienic to avoid food loss and secure healthy food for later consumption. ${ }^{446}$

Rations must be transported from the quartermaster to the preparation area and utilised according to the menu of the day. ${ }^{447}$ The main chef (shift leader) is responsible for the control and safekeeping of the rations. It is important that food be handled according to the first-in-first-out (FIFO) principle in the mess. This means that new items are stored behind the old items to ensure there is food rotation. Food expiry dates should always be reflected on the products.

The responsibility of environmental health service and hospitality personnel is to ensure that food is handled with care from the production to the consumption thereof. Food is to be monitored constantly to avoid damage to food, or poor hygienic practices in the kitchen. The mismanagement of food may allow contamination of food, which will result in food wastage. Food hygiene programmes are conducted to prevent poor practices in receiving, storing, preparing and serving food. ${ }^{448}$ Storage temperature should always be checked to ensure that it complies with the requirements prescribed for products ordered to avoid food wastage. ${ }^{449}$

An effective approach, aimed at reducing food wastage before cooking, is to optimise the type of catering model used by the mess. These catering models differ in their procurement and ordering of goods from outside suppliers to the unit. The food should be ordered according to food preference and the current market to minimise wastage by living-in members. The mess personnel have tasks and responsibilities in planning, 
preparing and managing food in the kitchen. This starts from the person ordering food through to the storeman who packs the food. Ration scale and unit strength may assist in meal planning as these are used as measuring instruments to prepare meals. Effective control and management in the mess is essential to reduce food wastage during the transportation, storage and preparation of food.

In the military, as in the hospitality sector, investing in prevention is the most effective and efficient way to combat food wastage. It is about controlling food wastage at consumption level, while the other measures are corrective; thus, occurring after consumption as food management practise. ${ }^{450}$ Prevention reduces the use of resources by adhering to mechanisms in place to ensure that the risk that is linked to the environmental, economic and social impacts when generating waste is minimised. ${ }^{451}$ Food wastage can also be prevented by improving food labelling, better planning in food preparations, and improving the packing and storing of food in the best available place at correct temperatures. ${ }^{452}$

\section{Researching food wastage management}

The FAO and the United Nations Environment Programme (UNEP) have created two indicators that monitor food processing at different levels in the food chain. The Food Loss Index monitors, the Food Loss Post-Harvest Index, and the Food Waste Index are still being developed and will monitor food wastage by retailers and consumers. The current study focused on the last part of the Food Waste Index: Public and household consumption (see Figure 1).

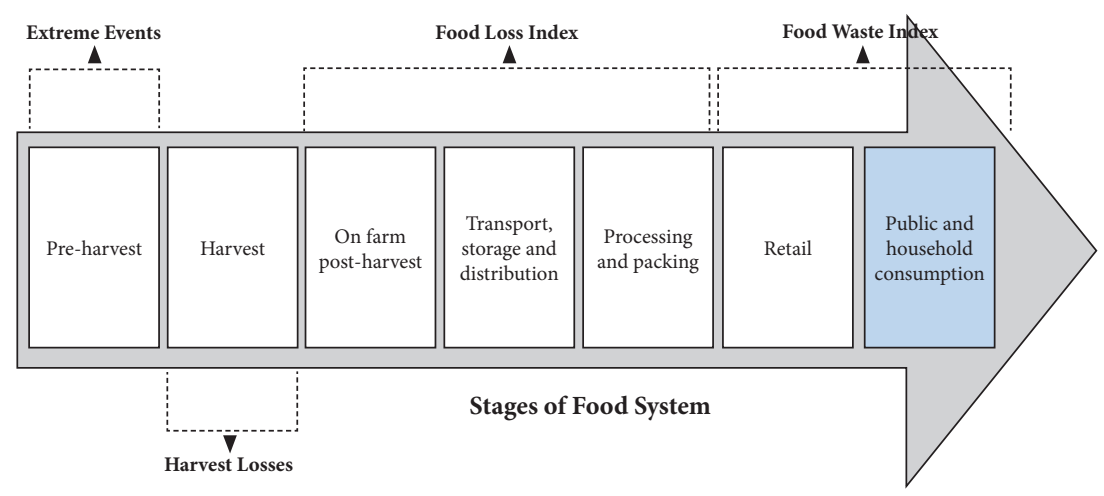

Figure 1: Scope of Food Loss Index along the food supply chain ${ }^{453}$

The aim of the current study was to analyse FWM at the SAMA mess. To reach this aim, the objectives identified were to:

- $\quad$ establish how the FWM system at the SAMA functions;

- determine the level of training of mess personnel in FWM in the kitchen; and

- $\quad$ provide recommendations to improve FWM at the SAMA mess. 
The study was conducted at the South African Military Academy (SAMA) mess. The SAMA was established in April 1950. It is a military unit of the SANDF and houses the Faculty of Military Science, Stellenbosch University. Initially, the SAMA had an agreement with the University of Pretoria to present Military Studies to permanent military officers at the Military College in Pretoria. However, in 1953, the SAMA permanently relocated to its current location in Saldanha Bay, with the first officers starting their studies in 1955. In 1961, the Faculty of Military Science (FMS) was officially established.

Saldanha Bay is approximately $105 \mathrm{~km}$ northwest of Cape Town in the West Coast District Municipality, in the Western Cape, South Africa. The SAMA was selected for the study because some of the authors are alumni of the SAMA and some are current lecturers in the FMS, and it made sense to conduct the study where access to the SAMA mess is not restricted. Figure 2 shows the location of the study area.

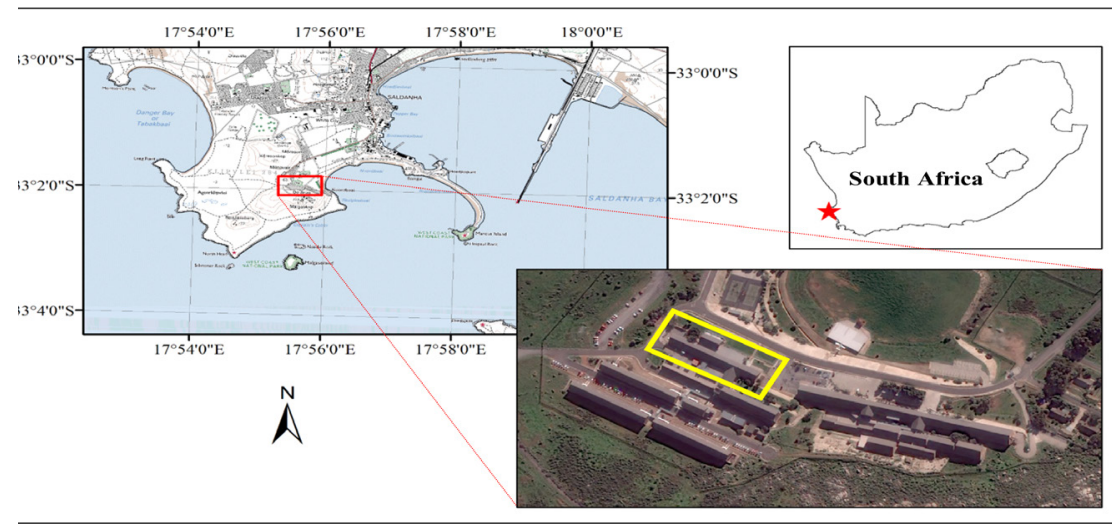

Figure 2: Orientation map showing the location of the SAMA (indicated by the red star). The SAMA mess building is indicated by the yellow rectangle $\mathrm{e}^{454}$

\section{Participants in the study}

All thirteen personnel working in the SAMA mess were invited to participate in the study. Because the mess personnel comprised a small and captive group, it was possible to invite all the participate. Ten participants gave consent to take part in the study. Institutional permission to conduct this study was obtained from the Commandant of the SAMA. Ethical clearance was requested and approved by the Stellenbosch University Research Ethics Committee. The participants completed and signed written consent forms before the study commenced to protect their rights to confidentiality of information. Throughout the study, the researcher secured participants' anonymity. 
To acquire relevant information from the participants in the study, primary data were collected in the form of an online semi-structured interview. Interview questions were formulated based on a combination of a thorough review of relevant literature and the researchers' own experience of military mess facilities. The interviews were guided by a protocol with a set of semi-structured questions, notes were taken for clarity, and answers were transcribed verbatim. The semi-structured interview questionnaire consisted of:

- 30 semi-structured interview questions, namely dichotomous questions (for basic validation);

- $\quad$ multiple-choice questions (to match expected outcomes); and

- $\quad$ open-ended questions (to collect feedback and/or suggestions).

The interview questionnaire was divided into three sections, namely biographical information, information on FWM, and information on training or education of participants on FWM. The questions asked to the participants are indicated in Table 1.

Table 1: Semi-structured interview questions

1. Age group? (18-29 years; 30-39 years; 40-49 years; 50-60 years)

2. Years of experience working in a mess

3. Years of experience working at the Military Academy mess

4. What type of a catering model is the Military Academy using?

5. How many meals does the mess prepare per day during the week?

6. How many meals does the mess prepare per day on weekends?

7. How many people on average eat in the mess during the week?

8. How many people on average eat in the mess during the weekend?

9. How is the scale of issue per meal for rations calculated at the mess?

10. What happens in the event where less people show up than what was calculated?

11. Is there a person who monitors the food expiry dates when receiving in the food in the mess?

12. Do you dispose of food that has exceeded its use-by-date \& how? What do you do with food that has exceeded its 'use-by' or 'best before' date?

13. How often do you receive fresh vegetables and fruits from the main store/ supplier?

14. How often do you receive starch from the main store/supplier?

15. How often do you receive meat from the main store/supplier? 
16. How often do you receive frozen vegetables?

17. What happens to the food wastage ("offcuts" such as vegetable peels and bones after de-boning of meat) during the preparation of the meal?

18. What happens to the food that is burnt at times of cooking?

19. What happens to the food that has been prepared for living-in members that were not consumed at all?

20. What happens to the leftover food on the plates after each meal?

21. How is the food waste currently stored outside the mess?

22. How often is the waste removed from sight and by whom?

23. Does the mess have any internal bins to support the segregation of food wastage (e.g. bin for raw uncooked vegetables/fruits or bin for cooked food and bones)?

24. How do you dispose of the food that has been prepared for living-in members that were not consumed?

25. How do you dispose of leftover food after each meal?

26. Are there any restrictions that may prevent the collection of disposed of food?

27. Does the School of Catering present modules regarding food wastage management in the kitchen?

28. Did you receive training on food wastage management on the courses you have completed?

29. Does the Military Academy mess have Standard Working Procedure or any document that gives guidance to the Chefs regarding food wastage in the mess, e.g. SWP?

30. Does the Military Academy have a public awareness campaign to discuss food wastage in the mess?

\section{Data collection}

Online semi-structured interviews were used to collect the data for this study using the Microsoft Teams (MS Teams) online collaborative platform. MS Teams was selected in order to adhere to social distancing measures as prescribed by SAMA and Stellenbosch University's COVID 19 protocols. The interviews took place between 7 and 18 September 2020. Each interview was recorded, and took approximately one hour to complete. The interviews were conducted in English, and were scheduled for after 14:00 when participants were not so busy in the kitchen.

The researcher developed a written interview schedule in advance to guide the interviews with ten participants, and provided probing examples where necessary. A limitation of this instrument is that an interview may go in an unintended direction at times; hence, the need for an interview schedule. 


\section{Data analysis}

Data analysis comprised the study of notes taken during each interview, and analysis of the interview recordings. Descriptive statistics (e.g. mean, maximum, minimum) using Microsoft Excel were generated to view and analyse the data. Data analysis comprised three phases:

- $\quad$ The first phase consisted of transcribing the interviews word for word searching for meaning. The data were extracted manually from transcripts building the framework for displaying and analysing data using underlying patterns in the data.

- The second phase consisted of the compilation of a thematic framework by grouping all similarities and differences in the data.

- Lastly, reporting of data results was done in the form of prominent verbatim quotes to illustrate the points made by participants. Such responses added richness and depth to the research report.

The participants' views and discussion about food wastage management at the SAMA

This section provides a detailed report on the results of the study according to the three sections mentioned above, namely biographical information of participants, results pertaining to FWM at the SAMA, and training or education of participants.

Biographical information of participants

Table 2: Demographic profile of participants

\begin{tabular}{|l|l|c|}
\hline \multicolumn{1}{|c|}{ Demographic profile } & \multicolumn{1}{c|}{ Years } & Percentage (\%) \\
\hline \multirow{4}{*}{ Experience working in a military mess } & 1-5 years & 30 \\
\cline { 2 - 3 } & 6-10 years & 20 \\
\cline { 2 - 3 } & $11-15$ years & 20 \\
\cline { 2 - 3 } & 16 years and more & 30 \\
\hline \multirow{3}{*}{ Experience working at the SAMA mess } & 1-5 years & 60 \\
\cline { 2 - 3 } & $6-10$ years & 30 \\
\cline { 2 - 3 } & 11 years and more & 10 \\
\hline
\end{tabular}

Biographical information of the participants was used to gain insight into the age, years of experience working in a military mess, and years of experience working at the Military Academy mess specifically (see Table 2). Although gathered, information regarding age was omitted from this article to protect the participants' anonymity. Ten out of a possible thirteen members participated in this study, and the data are moot when there is only one person in the group who fits a certain age group. ${ }^{455}$ 
The results show that three of the participants occupied managerial posts and seven were general chefs. Regarding "experience working in any military mess", 30 per cent (n= 3) of participants had 1 to 5 years' experience, 20 per cent $(n=2)$ had 6 to 10 years' experience, 20 per cent $(n=2)$ had 11 to 15 years' experience, and 30 per cent $(n=3)$ had more than 16 years' experience. Results also showed that the majority of participants (60 per cent; $n=6$ ) had 5 years or less experience working in the SAMA mess, while 30 per cent $(n=3)$ had 6 to 10 years' experience and 10 per cent $(n=1)$ had between 11 and 15 years of experience. The results show that the chefs working at the SAMA had good experience working in a military mess, with the majority ( 70 per cent) having more than 5 years' experience. The results also show that the majority of chefs ( 60 per cent) had 5 years' or less working experience at the SAMA, which might be related to instances where military members are promoted to a higher post and transferred to another unit. However, these reasons were not part of the scope of this study.

\section{Food wastage management at the SAMA}

The results from this section are presented under various themes related to the different questions asked to the participants (i.e. catering system, management of rations and food preparation, receiving and storage of food in the mess, handling of unavoidable food wastage, disposal of food, and measures in place to prevent food wastage). Only certain direct quotations received from the participants (P1 to P10) under each section are presented. All quotes from participants' responses are therefore reproduced verbatim and unedited. Although not all answers received from the participants are included in this article, summaries of responses and general discussions for each theme are included to validate the analysis of the results.

\section{Catering system}

All participants responded that the SAMA is using a conventional model and is in the process of moving towards commercialisation:

This one is just a normal army one. We have not commercialised so it is a conventional. It is a conventional mess, conventional you order meals from ASB [Army Support Base] (P1).

It's a conventional model, but we are moving towards commercialisation (P7).

The mess is an old kitchen system, I think it is conventional but they are currently sorting out commercialised because the process takes quite longer maybe about a year or two. They have already started the paperwork (P9).

\section{Management of rations and food preparation}

According to participants, there is a document that guides all military chefs on how they issue food per meal per person. This document is still under review by the SAMA: 
"We are using Ration Scale 1. The Ration Scale 1 is a document that specifies what type of food must be issued per person per meal per day."( P1) The Department of Defence Hospitality Services Manager Learner Manual affirms what the participants reported, namely that the SANDF, including SAMA, is using Ration Scale 1 (as amended), which is a list of foods and drinks specified in quantities that a soldier is allowed to consume per day. ${ }^{456}$ According to the Limpopo Department of Health, the purpose of a ration scale is to be able to cater in bulk for a nutritional meal for a group of people based on scientific international standards, and to cater within a regulated budget. ${ }^{457}$ Deuster et al. (2017) mention that the type of rations that military personnel receive depends on the day-to-day activities of the unit and the availability of equipment and employees to prepare the required meals. ${ }^{458}$ The ration quantity that is issued in the military is calculated according to the ration strength, scale of issue, and the number of meals provided that day. ${ }^{459}$

The results in this study indicate that the number of people eating in the mess during the week ranged between 250 and 350 per meal per day. This strength is supplied by the SAMA human resource (HR) section. The average number provided is 300 per meal per day. This number decreases significantly over weekends to an average of 150 per meal per day. Participant responses regarding weekday and weekend meal preparation revealed that, on average, 19 meals are cooked per week (including weekends). A weekly meal comprises three servings per day, which equates to 15 meals during weekdays: "Its 3 meals per day. That is breakfast, lunch, supper. For the weekdays, it's 15 meals" (P9). However, there was a lack of consistency in the answers given by participants regarding the weekend meals. Answers varied from between 4 to 6 meals over weekends, but 50 per cent $(n=5)$ of the participants agreed that only 4 meals are cooked on weekends:

Two meals per day on Saturday and Sunday that will be brunch and supper (P1).

That will be four meals (P3).

That is four meals on weekend. It is brunch and supper. Brunch is breakfast and lunch together. That is Saturday and Sunday (P6).

The participants all confirmed that, at the time of the study, SAMA was using the traditional catering system of three meals per day during weekdays, namely breakfast, lunch and supper with snacks in between. The brunch catering system on weekends entails an early morning light snack and a two-course meal per day. The provision of a written ration strength to the mess is the responsibility of the HR section. This verified ration strength is used to book meals in the mess for present living-in members residing in single sleeping quarters. This can therefore be considered a means to reduce food wastage during the weekdays.

\section{Receiving and storing food in the mess}

According to participants, there is inconsistency in suppliers delivering food on time (i.e. fresh fruit and vegetables), which affects food quality. The majority of participants 
stated that food is delivered once a week:

Supposedly once a week. Suppose it if things goes correctly, sometimes we don't receive for three weeks and then we receive three weeks at once and that's a problem. Then we will waste a lot. We try to work it out as fast as possible (P1).

Once a week, if they don't deliver that certain week, we must make more fresh vegetables and more salads in a week and distribute more to the students (P3).

The supplier comes once a week and it is on Thursdays. If the supplier does arrive that week then they do a double issue and we try to cook all the fresh vegetables that week. If there is still more by the end of that week, we then don't demand vegetables the following week until the one we have is finished (P9).

The results further indicate that frozen vegetables are delivered twice a month and starch products and meat are delivered twice a week.

The majority of participants indicated that quality control of the rations in the mess is the responsibility of the floor manager, also known as the ration clerk. The floor manager ensures that the issuing and cooking of food are prioritised according to the expiry date. However, some participants had alternate responses, stating that quality control is the responsibility of each chef: "It is the responsibility of all chefs to check the best-before and the use-by date before preparing a meal" (P10). They also indicated that the health inspectors are responsible for further examining quality control in the mess. All participants agreed that the different types of food rations are stored in the mess separately from one another and according to the required temperature and other conditions. From the responses of the participants, it was clear that the floor manager is ultimately responsible for quality control of the rations, including checking the bestbefore and expiry dates. This indicates that a standard operating procedure exists to conduct quality control of rations. However, some participants mentioned that it is the responsibility of each chef, which might be an indication that some confusion may exists regarding the responsibility of chefs to do quality checks. It might also be an indication that chefs at the SAMA take it upon themselves to double-check the quality of the rations to ensure suitability to the consumers.

\section{Handling of unavoidable food wastage}

Regarding the handling of unavoidable food wastage, the majority of participants mentioned that the food off-cuts during preparation are thrown in the pigswill:

That also goes into the pigswill (P1).

It goes to the pigswill (P3).

We put it in the pigswill (P9). 
Food off-cuts are small pieces of waste food that are cut off from larger pieces, such as fatty tissue and bones. The pigswill is given to local farmers who come to the SAMA and collect the pigswill once it is full: "There are two farmers that come and fetch the pigswill, I don't know who they are" (P1). See Figure 3 below for the pigswill containers being used at the SAMA officers' mess.
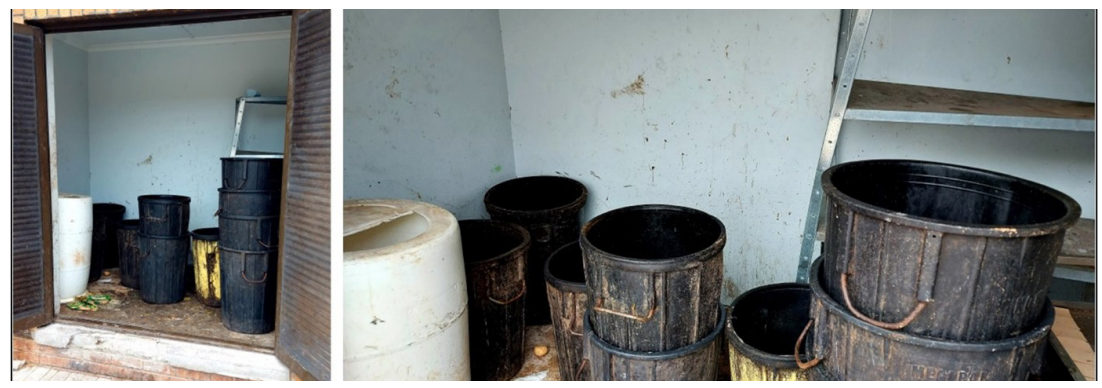

Figure 3: The pigswill containers used at the SAMA officers' mess

On a positive note, one participant actually made a vegetable garden behind the mess using the off cuts:

I want to tell you, from my personal point of view, on what I do with it. Like onions, the peel of the onions, the roots of the onions, you know the onion has got a root. I grow them; it's a creation of spring onions. If you could go at the back of the mess, you will see some of my spring onions there. I created a garden at the back (P4).

Figure 4 shows pictures of the vegetable garden started by one of the staff members of the SAMA officers' mess. The vegetable garden was planted by using leftover food from the kitchen, and is located behind the mess building and is maintained by the mess personnel.
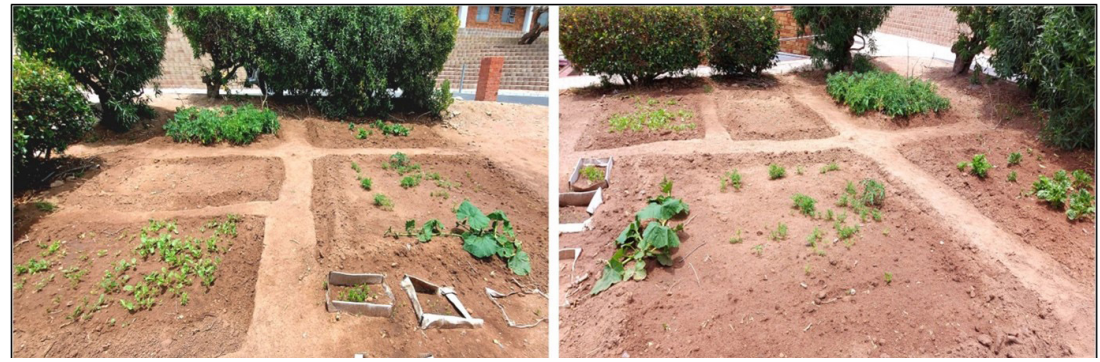

Figure 4: Vegetable garden created by a staff member of the SAMA officers' mess

All the participants answered that they hardly burn food and, if food gets burned, then it would be redirected to the pigswill: 
That is something very, very seldom. It is seldom. But if it burns and it's not consumable, we'll have to throw it away. But if so then you have to write the letter why, we have to throw away that food, but is very seldom to burn food (P1).

It is not often that food is burnt in the mess and everyone monitors their pots but if it should happen, it will go to the pigswill (P3).

If the food gets burnt, that is rare. But sometimes the food doesn't really, really gets burnt, it's just underneath. But we improvise to make everything edible. But the floor manager is the one that can sort that thing out (P7).

We don't normally burn food. Because they burn the chefs must sort it out themselves because if you are a chef you can't burn food. Then that's a problem, a real problem. It's an offence. If I issue that meal and if you are a chef for the shift leader, one of your chef burn the food you must answer and you must get that meal sorted out. We can't re-demand, the question will be why (P9).

Concerning expired food, the majority of participants said that food that has passed the expiry date is taken back to the SAMA quartermaster (QM) in the Logistics section:

We inform the stores and they come and fetch it and I don't know what they do with it thereafter (P3).

We don't dispose it, we return it to Logistics. We use the same format we use when we demand goods (P4).

If like for example, there is food that is expired, do we take it back to the logistics and logistics takes it back where it comes from. It's the floor manager who is the ration clerk that does that (P8).

\section{Disposal of food}

The majority of the participants mentioned that disposed food is stored in drums in a room with lockable doors at the back of the mess:

There is a storeroom, a pigswill store. It is a closed store with ventilation doors that is lockable (P1).

The pigswill [store] is a big room where all the big drums are with doors and it's locked. And we just keep the key in the mess (P2).

It is in stored in a room that has drums outside the mess. That place is locked. When people of pigswill come, the chief goes and open for them and they take the full drums and leave empty drums in that store (P3). 
There is a storeroom with bins outside, we lock it so cats don't go there.

It is opened every time they come and collect the pigswill (P8).

According to the participants, the pigswill is removed twice a week by contractors that have permits to access to the unit:

Twice a week, I will say (P2).

Those people come twice or three times a week at times (P3).

They come and fetch the food twice a week and they have permits (P8).

It was also mentioned by some participants that there is no contract in place for the pigswill:

No, pigswill is the only method used in the military academy to dispose food disposal, if you don't have a vegetable gardens or something like that to repurpose food, just dispose them. According to me, there is no contract in place $(\mathrm{P} 1)$.

Every second day the food is removed from the pigswill and there is a person who fetch the food but there is no contract in place but they are working on it (P9).

\section{Measures in place to prevent food wastage}

Results showed that additional raw food received is delivered and stored by the unit QM and measures are in place to use surplus food still fit for consumption as extra portions during functions or to cater for special events:

The extra food we take it down to savings at the quartermaster. There is savings at the QM where we put all the extra food, we use it when students want to have a braai or when students request for functions then we give them extra meat from that (P10).

Conversely, the majority of participants agreed that the leftover cooked food is repurposed into different meals:

We repurpose the food and make something else before it gets to be thrown away (P3).

What happened to me as an individual, I give a recycles which means that food goes on in a cooling process and then it's refrigerated, the next day it is used for breakfast (P4).

If it is after breakfast, such as eggs, and the food is re-usable, we use it for tea (P5). 
You see, normally when we have food that is extra, the people that did not book can be given the food. Or the people that were not full can come for second plates. The edible food we put it in the fridge and use it for tea time snack (P7).

Leftover food that cannot be preserved for future use is disposed of after each meal by throwing it in the pigswill:

No, pigswill is the only method used in the military academy to dispose food disposal, if you don't have a vegetable gardens or something like that to repurpose food, just dispose them (P1).

We prepare food as the strength given to us and whatever is leftover give it to the pigswill (P3).

Proactive management requires the mess personnel to think ahead, manage foreseeable risks, and devise strategies in advance in order to minimise food wastage. Reactive management, on the other hand, requires a response to situations as they arise. According to Alonso-Almeida and Bremser (2015), a reactive management strategy is mostly prioritised as it is expected to ensure the survival of the business. ${ }^{460}$ The most desirable option, however, is proactive management, because it has a positive effect on cutting costs. Furthermore, through proactive management, it is possible to take steps to reduce potential damage or risks.

On proactive and reactive ways of avoiding food wastage, participants demonstrated ways of avoiding food wastage by improvising the preparation, cooking and portioning of meals:

Okay, six months after the expiry date, we may still use dry rations because the area military health says it is still safe for consumption. But we must still check it before we cook it obviously ... If it is canned food, the same thing applies, we must check if the can is not damaged and if it has passed its expiry date, we can still use the can as it is. But when it comes to bread, milk and fresh fruit and veggies, that must be disposed immediately. We put an order at the medic and they send health officer to come and dispose of it. And then there's a disposal process but the disposal process is logistics (P1).

[W] give people extra fruits and vegetables, but when we have a shortage because of no deliveries we make use of whatever is extra in the fridge, maybe extra tomatoes (P7).

\section{Training or education of participants on food wastage management}

All participants revealed that the School of Catering, where military chefs are trained in the SANDF, presents a basic FWM module in their courses. The research results show that the majority of participants $(80$ per cent, $n=8)$ received training in FWM. Only two of the participants ( 20 per cent) had not received any training: 
Yes, I did during my own personal studies hotel management through Intec College (P1).

I think so, but the last time I did a course in School of Catering was in 1999 and that is about 21 years ago so I don't know if the syllabus has changed or it is a new things attached to the syllabus itself. But that time I was there was no food wastage management courses (P4).

Not yet, I will do it in the next course, they used to start at C4 or rank of a staff sergeant to teach about this but the curriculum has changed so even MSDS [Military Skills Development System] that started with basic chef course are now taught about food wastage management (P7).

With respect to standard working procedure of FWM, the results showed that most of the respondents (90 per cent, $n=9$ ) had never seen a document on FWM at the SAMA mess, which is quite significant for FWM at the SAMA. One participant mentioned that such a document does exist; yet, failed to provide the document after numerous attempts to acquire it ("Yes, I think so, but I will have to look for that document and ensure you get it"). The results of the study further showed that there had been no public awareness campaigns in or around the SAMA or at the West Coast in FWM. Another significant aspect derived from the study was that the participants themselves did not consider food wastage a problem - probably because the kitchen staff at the SAMA was managing food wastage as best they could and did not necessarily see the effect that poor FWM might be causing. This creates the realistic problem of effectively addressing food wastage at the SAMA, especially if the kitchen staff and chefs do not consider it a priority. The lack of awareness among the local community, kitchen staff, students and faculty members about the impact of food wastage may unconsciously cause existing food wastage or lead to an increase in food wastage.

\section{Conclusion}

The focus of this study was to analyse food wastage management (FWM) at the SAMA mess. The SAMA mess follows a conventional catering model where the state provides all the labour and rations needed for the functioning of the mess, as well as maintenance of mess facilities. Rations are delivered at a central depot and food is distributed to the unit based on its stated demand. The food is prepared according to the prescribed ration scale and ration strength submitted to the mess. This system may change in future with a move towards commercialisation.

Results indicated that during weekdays, food wastage is prevented by preparing food according to the strength provided by the HR section. On weekends, a meal register is used by all living-in members to book meals in advance. This is used to calculate savings on rations over the weekend and as means of reducing food wastage. Unused but still fit for consumption food is reused by converting it into a secondary meal for tea break. Alternatively, it is redistributed as a second option for a meal. Unavoidable food waste is removed from the kitchen and discarded as pigswill. Although there is no consistency in delivering fresh fruit and vegetables at SAMA, mess personnel 
have managed to mitigate or minimise food wastage by distributing more fruits and vegetables to the students to prevent its loss or spoilage and by correctly storing each type of commodity to avoid contamination of food. This option minimises the potential of food entering the waste stream and has a financial and environmental benefit. ${ }^{461}$ The participants confirmed that they ensured that perishable cooked food is utilised on the day of preparation and that food is reused for another purposes to minimise wastage. 'Re-use' refers to using the material again for a similar or different purpose without altering its physical form, thus removing it from the waste stream. ${ }^{462}$ Re-using food limits the impact on natural resources and will have a positive effect on food security and sustainability, especially in terms of poor societies. ${ }^{463}$ It is better to redistribute edible food to humans before discarding it or using it for animal feed. The option of donating re-usable food to less fortunate people is the least favourite due to the societal impact it might have should a person fall ill from eating the donated food. As a result, although the poverty rate in the area is fairly high, businesses generally opt for the disposal of food. This complies with section 61 of the Consumer Protection Act (68 of 2008), where a manufacturer, supplier, or retailer of goods may be held liable for the detrimental effects caused from providing unsafe goods, flaws or threats by goods provided, product failure, or insufficient information provided to the customer relating to the danger that may result from using the product. ${ }^{464}$

The results further showed that, although SAMA mess personnel are trained in FWM, such training is limited. One of the most significant conclusions relates to the fact that no standing working procedures (SWPs) are in place and no initiatives exist to advocate awareness campaigns in order to implement better managerial strategies for further reduction of food wastage. Also of concern is that the kitchen staff and chefs at the SAMA do not consider FWM a problem, which might limit initiatives to addressing food wastage effectively at the SAMA. No specific reason was provided for the comment that FWM is not a problem, but it is possible that the kitchen staff at the SAMA is doing what must be done regarding the management of food wastage and therefore do not necessarily see the impacts associated with food wastage.

Although the results of the study indicated a generally good food wastage prevention regime in place at the SAMA mess, it is recommended that training and awareness campaigns be offered to reduce food wastage further. It is also recommended that relevant documentation, such as standing working procedures (SWPs), on FWM need to be made available to all mess personnel, students and faculty staff. The benefit of involving students and faculty staff in awareness campaigns might create a positive attitude towards FWM not only at the SAMA, but may even spill over into their personal lives. It might also be feasible to organise awareness campaigns for the local community and to include local businesses as sponsors and ambassadors of such campaigns to motivate the public to take action against food wastage. The potential benefits of conducting awareness campaigns will bring change to the FWM at the SAMA and inadvertently save time, money and resources and improve the overall efficiency and cost-effectiveness of food services at the SAMA. 
It is recommended that meal bookings be implemented during weekdays, as is the case over weekends. Some of the wastage can be attributed to members skipping meals during the week when there is no booking system in place. If a meal is booked and a person does not attend, such person should be held accountable for the payment of the meals he or she did not consume.

It is further recommended that policies and awareness programmes, which specifically address FWM in the military, be in place and visible to all mess personnel at all units.

A limitation identified during this study was the size of the population. This study was limited to the thirteen members working at the SAMA mess, and ten participated in this study. The small size of the sample makes it difficult to extrapolate the results achieved in this study to other units in the SANDF. The small sample also undermines the internal and external validity of the study. It is therefore recommended that further research on this topic involve more SANDF units to obtain a better understanding of analysing FWM in the SANDF. For such a study, it might be feasible to include military messes from the different Arms of Services (i.e. SA Army, SA Navy, SA Air Force and SA Medical Health Services), which will provide results that are more inclusive of FWM in the SANDF. It is lastly recommended that an area for future research also include the attitudes and perspectives of food consumers, such as students who dine at the SAMA.

As a last thought, currently the pigswill is given to two local farmers as a support initiative to the local community. In addition, it might also be feasible for the SAMA to draft a service level agreement with a pigswill company to receive incentives and generate additional funds from rendering these services. Money received from such an initiative can be directed towards training and education of mess personnel and funding of awareness campaigns in FWM. 


\section{ENDNOTES}

${ }^{374} \mathrm{Cdr}$ (Prof.) HAP Smit and Dr I Henrico are senior lecturers in the Department of Military Geography at the Faculty of Military Science (Stellenbosch University) and were the supervisors for Maj NP Moss who successfully completed her BMil Hons in Military Geography with this research project.

${ }^{375}$ In the SANDF, a 'living-in member' is a person permanently staying in military accommodation and normally eating at the military mess associated with this accommodation.

${ }^{376}$ FAO. "The state of food and agriculture". 2019. <http://www.fao.org/3/ca6030en/ca6030en. pdf $>$ Accessed on 21 September 2020.

${ }^{377}$ GT Miller \& S Spoolman. Living in the environment: Principles, connections, and solutions $\left(14^{\text {th }}\right.$ ed). Belmont, CA: Thompson Brooks/Cole, 2011.

${ }^{378}$ S Bringezu, A Ramaswami, H Schandl, M O’Brien, R Pelton, J Acquatella, E Ayuk, A Chiu, F Flanegin, J Fry \& S Giljum. Assessing global resource use: A system approach to resource efficiency and pollution reduction. Paris: International Resource Panel of the United Nations Environmental Programme, 2017.

${ }^{379}$ D Satterthwaite, G McGranahan \& C Tacoli. "Urbanization and its implications for food and farming". Philosophical Transactions of the Royal Society B: Biological Sciences 365/1554. 2010. 2809-2820.

${ }^{380}$ S Jain, D Newman, R Cepeda-Márquez \& K Zeller. "Global food waste management: An implementation guide for cities". World Biogas Association, 2018, 145. $<$ https:// www.worldbiogas-association.org/wp-content/uploads/2018/05/Global-Food-WasteManagement-Full-report-pdf.pdf $>$ Accessed on 27 September 2020.

${ }^{381}$ FAO op. cit.

${ }^{382}$ J Marthinsen, P Sundt, O Kaysen \& K Kirkevaag. Prevention of food waste in restaurants, hotels, canteens and catering. Copenhagen: Nordic Council of Ministers, 2012. doi: http://dx.doi.org/10.6027/TN2012-537

${ }^{383}$ S Priestley. Food waste briefing paper. United Kingdom: House of Commons Library, 2016, 44.

${ }^{384}$ South African Qualifications Authority. Cook: National Occupational Qualification (OFO CODE 512101): Learner manual. Department of Defence, Pretoria, 2017.

${ }^{385}$ Department of Defence. "South African Defence Review 2015". 2015. <https://static.pmg.org. za/170512review.pdf $>$ Accessed on 23 September 2020.

${ }^{386}$ L Nguyen. "Food waste management in the hospitality industry: Case study: Clarion Hotel Helsinki". Bachelor's Degree thesis. Haaga-Helia University of Applied Sciences, 2018.

${ }^{387}$ Garcia-Garcia, G., Woolley, E., Rahimifard, S., Colwill, J., White, R., \& Needham, L. (2017). A methodology for sustainable management of food waste. Waste and Biomass Valorization, 8(6), 2209-2227.

${ }^{388}$ JT Marx. "Military integrated environmental management at the Donkergat military-training area". PhD dissertation. Stellenbosch University, 2014.

${ }^{389}$ R Jackson. "Most people waste more food than they think - here's how to fix it". National Geographic - Environment. 2021. <https://www.nationalgeographic.com/ environment/article/people-waste-more-food-than-they-think-psychology $>$ Accessed 19 January 2021.

${ }^{390}$ SH Oelofse \& A Nahman. "Estimating the magnitude of food waste generated in South Africa". Waste Management \& Research 31/1. 2013. 80-86.

391 Ibid. 
${ }^{392}$ P Notten, T Bole-Rentel \& N Rambaran. Developing an understanding of the energy implications of wasted food and waste disposal: Understanding the food energy water nexus. South Africa: WWF-SA, 2014.

${ }^{393}$ A Nahman, W de Lange, S Oelofse \& L Godfrey. "The costs of household food waste in South Africa”. Waste Management 32/11. 2012. 2147-2153.

${ }^{394}$ ML Marais, Y Smit, N Koen \& E Lötze. "Are the attitudes and practices of foodservice managers, catering personnel and students contributing to excessive food wastage at Stellenbosch University?" South African Journal of Clinical Nutrition 30/3. 2017. 6067; CH Mabaso \& D Hewson. "Employees' perceptions of food waste management in hotels". African Journal of Hospitality, Tourism and Leisure 7/4. 2018. 1-15; L

Sakaguchi, N Pak \& MD Potts. "Tackling the issue of food waste in restaurants: Options for measurement method, reduction and behavioral change." Journal of Cleaner Production 180. 2018. 430-436; S Schiavone, CP Pelullo \& F Attena. "Patient evaluation of food waste in three hospitals in Southern Italy". International Journal of Environmental Research and Public Health 16/22. 2019. 4330.

${ }^{395}$ Marais et al. op. cit.

${ }^{396}$ Mabaso \& Hewson op. cit.

${ }^{397}$ N Jenkin \& L de Vries. "Loss and waste: Facts and futures: Taking steps towards a more sustainable food future". WWF-SA, 2017. <https://www.researchgate.net/ publication/322266191_Food_Loss_and_Waste_Facts_and_Futures_Taking_steps towards_a_more_sustainable_food_future $>$ Accessed on 24 August 2020.

${ }^{398}$ Jain et al. op. cit.

${ }^{399}$ World Health Organization. "Research ethics committees: Basic concepts for capacitybuilding”, 2009, 76. <www.who.int/ethics/publications/en/\%0Ahttp://www.who.int/ ethics/Ethics_basic_concepts_ENG.pdf $>$ Accessed on 23 August 2020.

${ }^{400}$ Priestley op. cit.

${ }^{401}$ FAO. "Food wastage footprint: Impacts on natural resources, Summary report", 2013, 9. $<$ http://www.fao.org/3/i3347e/i3347e.pdf > Accessed on 21 August 2020; GL Riley. Food waste: Practices, management and challenges. Waste and Waste Management. New York, NY: Nova Science, 2016, 123.

${ }^{402} \mathrm{FAO}$, Food wastage footprint op. cit.

${ }^{403}$ Mabaso \& Hewson op. cit.

${ }^{404}$ Nguyen op. cit.

${ }^{405}$ A Enos. "Assessing the socio-economic impact of food waste among international students". MA thesis. Szent István University, 2019. <https://www.researchgate.net/ publication/332353148_Assessing_the_Socio-Economic_Impact_of_Food_Waste Among_International_Students $>$ Accessed on 26 June 2020.

${ }^{406}$ Mabaso \& Hewson op. cit.

${ }^{407} \mathrm{Ibid}$; Department of Environmental Affairs. "National Waste Management Strategy", 2011, 75. $<$ https://www.environment.gov.za/sites/default/files/docs/nationalwaste_management strategy.pdf $>$ Accessed on 18 September 2020.

${ }^{408} \mathrm{FAO}$, The state of food and agriculture op. cit.

${ }^{409}$ Barilla Center for Food \& Nutrition. "Food waste: Causes, impacts and proposals”, 2012, $<$ httpts://www.barillacfn.com/en/publications/food-waste-causes-impacts-andproposals.pdf $>$ Accessed 08 October 2020.

${ }^{410}$ Ibid.

${ }^{411} \mathrm{FAO}$, The state of food and agriculture op. cit; Enos op. cit.

${ }^{412} \mathrm{FAO}$, The state of food and agriculture op. cit.

${ }^{413}$ Ibid.

${ }^{414}$ Shift. "Domestic food waste: Insights report", 2014. <https://shiftdesign.org/content/ uploads/2014/09/Shift_Food-Waste-insights.pdf> Accessed on 5 January 2021. 
${ }^{415}$ C Hamilton, R Denniss \& DG. Baker. Wasteful consumption in Australia. Canberra: The Australia Institute, 2005.

${ }^{416}$ Buchner et al. op. cit.

${ }^{417}$ JRC Sandaruwani \& WAC Gnanapala. "Food wastage and its impacts on sustainable business operations: A study on Sri Lankan tourist hotels". Procedia Food Science 6. 2016. $133-135$.

${ }^{418} \mathrm{FAO}$, The state of food and agriculture op. cit.

${ }^{419} \mathrm{Ibid}$.

${ }^{420}$ Enos op. cit.

${ }^{421}$ Â Stenmarck, C Jensen, T Quested, G Moates, M Buksti, B Cseh, S Juul, A Parry, A Politano, B Redlingshofer \& S Scherhaufer. Estimates of European food waste levels. Sweden: IVL Swedish Environmental Research Institute, 2016.

422 JC Buzby, H Farah-Wells \& J Hyman. "The estimated amount, value, and calories of postharvest food losses at the retail and consumer levels in the United States". USDAERS Economic Information Bulletin. 2014. 121.

${ }^{423} \mathrm{~S}$ Yaqub. "Social and socio-demographic effects on food waste: The case of suboptimal food". MA thesis. Norwegian University of Life Sciences, 2016. <https://core.ac.uk/ download/pdf/154672268.pdf $>$ Accessed on 17 August 2020.

${ }^{424}$ CK Chrobog. "Wasted: Understanding the economic and social impact of food waste". MA thesis. Brazilian School of Public and Business Administration, 2014.

${ }^{425}$ Enos op. cit.

${ }^{426}$ G Kibri. "Food waste impacts on climate change and water resources". Research on community-based environmental and sustainability education model, April 2017. $<$ https://www.researchgate.net/publication/316547640_Food_Waste_Impacts_on_ Climate_Change_Water_Resources $>$ Accessed on 20 January 2021.

${ }^{427}$ FAO. "Toolkit: Reducing the food wastage footprint", 2013. <http://www.fao.org/3/i3342e/ i3342e.pdf $>$ Accessed on 21 August 2020.

${ }^{428}$ Nguyen op. cit.

${ }^{429}$ Committee on World Food Security. "Food losses and waste in the context of sustainable food systems: A report by the High Level Panel of Experts on Food Security and Nutrition", 2014. $<$ http://www.fao.org/3/i3901e/i3901e.pdf $>$ Accessed on 28 August 2020.

${ }^{430} \mathrm{M}$ Bagherzadeh, M Inamura \& H Jeong. Food waste along the food chain. OECD Food, Agriculture and Fisheries Papers, No. 71. Paris: OECD Publishing, 2014.

${ }^{431}$ Ibid.

${ }^{432}$ C Chadderton, CM Foran, G Rodriguez, D Gilbert, SD Cosper \& I Linkov. "Decision support for selection of food waste technologies at military installations". Journal of Cleaner Production 141. 2017. 267-277; SD Cosper, DS Gilbert, IE MacAllister, MZ Rahman, J Ricketts, SR Rock \& G Rodriguez. "Feasibility study of food waste co-digestion at US Army installations". Defense Technical Information Center, 2017. $<$ https://apps. dtic.mil/sti/citations/AD1038188> Accessed on 31 September 2020; EE Hubbard, A Villadsen, P Rathje, CC Jensen, M Haselbach \& B Sakintuna. Planning green in cities and military installations. In: M. Goodsite, S. Juhola (eds). Green defense technology. NATO Science for Peace and Security Series C: Environmental Security. Springer, Dordrecht. 2017, 253-268<https://doi.org/10.1007/978-94-017-7600-4 12>

Accessed on 30 September 2020.

${ }^{433}$ Republic of South Africa. "National Environmental Management: Waste Act 59 of 2008". Government Gazette 525/32000. 2008. <www.environment.gov. za\%2Fsites\%2Fdefault\%2Ffiles\%2Flegislations\%2Fnema_amendment_act59. pdf\&clen $=1986735 \&$ chunk $=$ true $>$ Accessed on 25 September 2020.

${ }^{434}$ FAO, Food wastage footprint op. cit. 
${ }^{435}$ S Rock \& A Lan. "Food waste reduction in military kitchens: A tracking technology demonstration at Fort Jackson". US Environmental Protection Agency, 2019. <https:// cfpub.epa.gov/si/si_public_record_Report.cfm?dirEntryId=346767\&Lab=NRMRL $>$ Accessed on 13 August $20 \overline{2} 0$.

${ }^{436}$ VF Medina, M Wynter, SA Waisner, S Cosper \& G Rodriguez. The Army Net Zero Waste Program and its implications for energy: In: I. Linkov (ed). Sustainable cities and military installations. NATO Science for Peace and Security Series: C: Environmental Security. Springer, Dordrecht. 2013, 263-281. https://doi.org/10.1007/978-94-0077161-1_13>Accessed on 08 October 2020 .

${ }^{437}$ Department of Defence. Logistics instruction no. 81/2019: Commercialised Catering Model for DOD Clubs/Messes. Pretoria, 2019.

${ }^{438}$ Department of Defence. Hospitality services manager: Learner manual. Pretoria, 2018.

${ }^{439}$ Department of Defence op. cit.

${ }^{440}$ Department of Defence. Kitchen hand: Learner Manual. Pretoria, 2018 op. cit.

${ }^{441}$ Department of Defence 2018 op. cit.

${ }^{442}$ South African Qualifications Authority 2017.

${ }^{443}$ M Sako. "Outsourcing and offshoring: Implications for productivity of business services". Oxford Review of Economic Policy 22/4. 2006. 499-512.

${ }^{444}$ S Bera. "The concept of outsourcing”. IOSR Journal of Computer Engineering 19/4. 2017. $37-39$.

${ }^{445}$ Department of Defence. Kitchen Hand National Occupational Qualification, OFO:512101 learner manual. Pretoria, 2018.

${ }^{446}$ Department of Defence, 2018 op. cit.

${ }^{447}$ Ibid.

${ }^{448}$ Department of Defence. Hospitality services manager: Learner manual. Pretoria, 2018.

${ }^{449}$ South African Qualifications Authority 2017.

${ }^{450}$ Department of Defence. Hospitality services manager: Learner manual. Pretoria, 2018.

${ }^{451}$ South African Government. "White Paper on integrated pollution and waste management for South Africa: A policy on pollution prevention, waste minimisation, impact control and remediation", 1998. <https://www.environment.gov.za/sites/default/ files/legislations/integrated_pollution-and_wastemanagement_1.pdf $>$ Accessed on 8 October 2020.

${ }^{452}$ E Papargyropoulou, N Wright, R Lozano, J Steinberger, R Padfield \& Z Ujang. "Conceptual framework for the study of food waste generation and prevention in the hospitality sector". Waste Management 49. 2016. 326-336.

${ }^{453} \mathrm{FAO}$, The state of food and agriculture op. cit.

${ }^{454}$ Map copyright (C) 2020 CDNGI; Image credit: GEO Data Design, CNES 2020).

${ }^{455}$ M Cleary, J Horsfall, \& M Hayter. Data collection and sampling in qualitative research: does size matter? Journal of advanced nursing. 2014. 473-475.

${ }^{456}$ South African Qualifications Authority 2017.

${ }^{457}$ Limpopo Department of Health. "Food ration scales for hospitals and health institutions", Vol. 3, 2001. <http://policyresearch.limpopo.gov.za/bitstream/handle/123456789/874/ Food\%20ration\%20scales\%20for\%20hospitals\%20V3.pdf?sequence=1> Accessed on 14 October 2020.

${ }^{458}$ PA Deuster, T Kemmer, L Tubbs, S Zeno \& C Minnick. "The Special Operations Forces nutrition guide", 2017, 255. <https://navyseals.com/wp-content/uploads/2012/12/ special-operations-nutrition-guide.pdf $>$ Accessed on 14 October 2020.

${ }^{459}$ Department of Defence. Hospitality services manager: Learner manual. Pretoria, 2018. 
${ }^{460}$ M Alonso-Almeida, K Bremser \& J Llach. "Proactive and reactive strategies deployed by restaurants in times of crisis: Effects on capabilities, organization and competitive advantage". International Journal of Contemporary Hospitality Management 27/7. 2015. 1641-1661.

${ }^{461}$ Rock \& Lan op. cit.

${ }^{462}$ Department of Environmental Affairs op. cit.

${ }^{463}$ National Geographic Society. "Food safety and security", 2021.

$<$ https://www.nationalgeographic.org/topics/food-safety-and-

security/?q=\&page $=1 \&$ per_page $=25>$ Accessed on 23 February 2021.

${ }^{464}$ South African Government. "Consumer Protection Act 68 of 2008". Government Gazette 526/32186. 2008. <https://www.gov.za/sites/default/files/gcis document/201409/321864670.pdf $>$ Accessed on 21 August 2020. 